OPEN ACCESS

Edited by:

Noriyuki Koibuchi,

Gunma University, Japan

Reviewed by:

Laura Sterian Ward,

State University of Campinas, Brazil

Ming-Chi Lu,

Dalin Tzu Chi Hospital, Taiwan

${ }^{*}$ Correspondence: Jae Hoon Chung

thyroid@skku.edu

${ }^{\text {t}}$ These authors have contributed equally to this work

Specialty section: This article was submitted to

Thyroid Endocrinology,

a section of the journal

Frontiers in Endocrinology

Received: 15 March 2021 Accepted: 26 April 2021

Published: 13 May 2021

Citation:

Sohn SY, Seo GH and Chung JH (2021) Risk of All-Cause Mortality

in Levothyroxine-Treated

Hypothyroid Patients: A Nationwide Korean Cohort Study.

Front. Endocrinol. 12:680647. doi: 10.3389/fendo.2021.680647

\section{Risk of All-Cause Mortality in Levothyroxine-Treated Hypothyroid Patients: A Nationwide Korean Cohort Study}

\author{
Seo Young Sohn ${ }^{1 \dagger}$, Gi Hyeon $\mathrm{Seo}^{2+}$ and Jae Hoon Chung ${ }^{3 *}$ \\ ${ }^{1}$ Division of Endocrinology and Metabolism, Department of Internal Medicine, Myongji Hospital, Hanyang University College \\ of Medicine, Goyang, South Korea, ${ }^{2}$ Department of Healthcare Review and Assessment Committee, Health Insurance \\ Review and Assessment Service, Wonju, South Korea, ${ }^{3}$ Division of Endocrinology and Metabolism, Department of Medicine \\ and Thyroid Center, Samsung Medical Center, Sungkyunkwan University School of Medicine, Seoul, South Korea
}

Background: Although hypothyroidism is associated with various comorbidities, its relationship with increased all-cause mortality remains controversial. The aim of this nationwide retrospective cohort study was to investigate whether hypothyroid patients treated with levothyroxine had increased mortality compared to controls.

Methods: Hypothyroid subjects were identified through the Korean National Health Insurance Service Claims database between 2008 and 2017. Hypothyroidism in this study was defined as overt hypothyroidism treated with long-term prescription of levothyroxine (>6 months). After 1:3 age-, sex- and index year-matching, 501,882 patients with newly diagnosed hypothyroidism and 1,505,646 controls without hypothyroidism were included.

Results: During a mean follow-up of 6 years, 25,954 (5.2\%) hypothyroid patients and 59,105 (3.9\%) controls died. Hypothyroidism was significantly associated with increased all-cause mortality (adjusted hazard ratio [HR], 1.14; 95\% confidence interval [Cl] 1.121.16) even with levothyroxine treatment. When stratified by age, sex, and cardiovascular disease risk, independent associations between hypothyroidism and mortality remained significant in all subgroups. The risk of mortality was higher in the $<65$ age group (HR: 1.25, 95\% Cl: 1.22-1.29), men (HR: 1.28, 95\% Cl: 1.25-1.31), and the high cardiovascular disease risk group (HR: $1.31,95 \% \mathrm{Cl}: 1.29-1.34)$. The mortality rate of hypothyroid patients was highest within 1 year of treatment and decreased with time.

Conclusion: This nationwide, population-based cohort study showed that all-cause mortality was significantly higher in levothyroxine-treated hypothyroid patients than in nonhypothyroid controls. This association remained significant regardless of age, sex, and cardiovascular disease risk.

Keywords: hypothyroidism, mortality, levothyroxine, cohort study, cardiovascular disease 


\section{INTRODUCTION}

Hypothyroidism is a common endocrine disease, and its incidence and prevalence vary depending on the population being studied (1-3). In Korea, the reported incidence and prevalence of hypothyroidism, when defined as overt hypothyroidism with thyroid hormone prescription of $>60$ days, were 2.26 and 14.28 per 1,000 individuals, respectively (2).

The etiology of hypothyroidism includes various conditions. Chronic autoimmune thyroiditis is the major subtype of hypothyroidism in iodine-sufficient areas of the world (4). However, non-autoimmune hypothyroidism has been reported as the most common cause of hypothyroidism in Korea (5). Regardless of cause, hypothyroidism is associated with a number of well-characterized metabolic changes, such as hyperlipidemia, hypertension, and coagulopathy, as well as endothelial dysfunction and cardiovascular disorders (6-10), all of which could theoretically lead to increased mortality. However, studies of hypothyroidism have yielded considerable variation in mortality data (11-24). Some studies have found an increased risk of mortality in hypothyroid patients $(12-14,16,17,19,21-$ $24)$, but others have not $(11,15,18,20)$. Possible reasons for such inconsistencies may be heterogeneity between studies in terms of definition and severity of hypothyroidism, characteristics of participants, selection of the control population, and controls for comorbidities.

In most patients, hypothyroidism is permanent and requires lifelong treatment. Standard treatment involves the administration of thyroid hormones to maintain serum thyroid-stimulating hormone (TSH) levels within the reference range (25). Most patients become clinically euthyroid once TSH levels return to normal. However, recovery of TSH levels might not reflect the normalization of hypothyroidism-mediated metabolic changes (26, 27), suggesting that mortality risk may persist in hypothyroid patients even with treatment.

To date, a number of cohort studies and meta-analyses have investigated the relationship between hypothyroidism and mortality (11-24, 28-38). However, most have been restricted to subjects with subclinical hypothyroidism $(17,20$, $21,28,29,33,34,38)$ and some studies have defined hypothyroidism based on only one TSH level measurement $(13,15,22,28,30,37)$. Therefore, these studies may not represent patients with hypothyroidism who require long-term thyroid hormone replacement.

In this nationwide retrospective cohort study, we investigated all-cause mortality risks of hypothyroid patients undergoing long-term levothyroxine therapy compared to age- and sexmatched control subjects.

\section{METHODS}

\section{Data Source}

This nationwide retrospective cohort study was based on the Korean National Health Insurance (NHI) database provided by the Health Insurance Review and Assessment Service (HIRA).
The NHI is the only public medical insurance system operated by the Korean government and membership is compulsory. To claim payments for patient care, all clinics and hospitals in Korea are required to submit data including personal identification number, diagnosis, and prescription information to the HIRA. Therefore, the HIRA database includes claims for the entire South Korean population and comprises patient demographics, diagnosis information based on the International Classification of Diseases, $10^{\text {th }}$ Revision (ICD-10) codes, all inpatient and outpatient claims data, interventions, and prescriptions. HIRA de-identifies patient data in accordance with the Act on the Protection of Personal Information Maintained by Public Agencies.

\section{Study Population}

Hypothyroidism cohort. In this study, claims data for levothyroxine prescriptions from 2008 to 2017 were evaluated to define the incidence of hypothyroidism. Hypothyroidism in this study was defined as overt hypothyroidism with long-term prescription of levothyroxine ( $>6$ months). Only subjects aged $18-90$ years at the time of prescription were included. A one-year washout period was applied to newly diagnosed cases of hypothyroidism. When a thyroid hormone is prescribed, it is usually repeated within one year in clinical practice. Therefore, we only included patients with a minimum washout period of 1 year. The washout period was defined as the period between January 2007 and the date of first prescription (the "index date"). The exclusion criteria were as follows: (i) a diagnosis of thyroid cancer at any time or a history of thyroidectomy or radioactive iodine treatment to exclude any effects of iatrogenic thyrotoxicosis; (ii) short-term prescription of thyroid hormones ( $<180$ days) to avoid inclusion of transient hypothyroidism; and (iii) death within 6 months from the index date. Selection of the hypothyroidism cohort is illustrated in Figure 1.

Control cohort. Data for non-hypothyroid subjects (the control cohort) were also retrieved from the HIRA database. Individuals who received thyroid hormones or had a diagnosis of thyroid dysfunction-related diseases (ICD-10 code: E03.8, E03.9, E06.3) during the study period were excluded. In addition, the same exclusion criteria as in the hypothyroidism cohort were applied before matching the hypothyroidism cohort. Each hypothyroidism case was then matched to three nonhypothyroidism control individuals (1:3 matching) based on age, sex, and index date.

\section{Comorbidity}

Comorbidities were mainly selected based on metabolic abnormalities related to hypothyroidism. Hypothyroidism is closely associated with cardiovascular risk factors that lead to cardiovascular events (6-10). Decreased hemodynamics in the circulatory system also lead to declines in glomerular filtration rate (GFR) in severe hypothyroidism (39). As cancer is the most common cause of death in Korea, we adjusted for the presence of malignancy because the primary endpoint was all-cause mortality (40). 


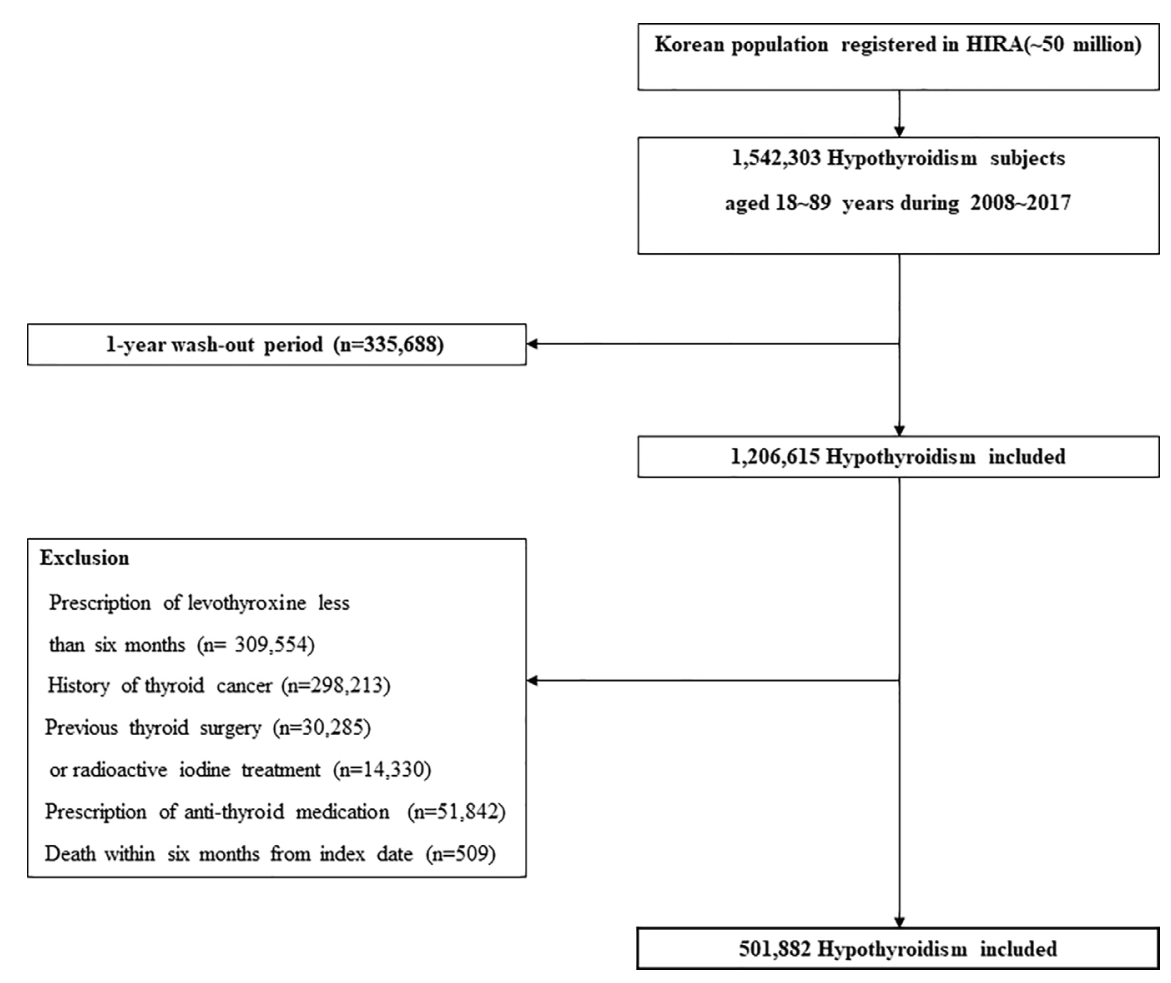

FIGURE 1 | Selection of the hypothyroidism cohort.

Baseline comorbidities were identified according to their respective ICD-10 codes: diabetes mellitus (E10-E14), hypertension (I10), congestive heart failure (I50), myocardial infarction (MI) (I21, I22, I25.2), stroke (I60-I64, I69), chronic kidney disease (N17-N19), and malignancy (C code). A preexisting comorbidity was defined as a disease diagnosed in at least three outpatient visits in the 1-year period preceding the index date. In cases of MI, stroke, and heart failure, inpatient hospitalization with records of any of their corresponding ICD codes as primary diagnosis was also defined as comorbidities.

\section{Mortality}

The primary outcome of this study was all-cause mortality. Mortality was recorded in the NHI cohort based on the database of the Ministry of Public Administration and Security, which compulsorily receives all reports on deaths through official death notices. Cases and times of death from inception to December 31, 2018, were identified for all subjects.

\section{Statistical Analysis}

The chi-square test was used to compare proportions and categorical variables between the hypothyroid and control cohorts. Student's $t$ test was used for comparisons of mean age between two groups. Crude incidence rates for mortality were calculated as the number of deaths per 1000 person-years. The incidence rates were further stratified by age ( $<65$ and $\geq 65$ years), sex, and cardiovascular disease (CVD) risk (high CVD vs. low CVD risk). High CVD risk was defined as the presence of hypertension, diabetes mellitus, or prevalent CVD (MI, stroke, and heart failure). Kaplan-Meier curves were used to describe and compare cumulative survival rates between the hypothyroid and control cohorts. The follow-up period started on the index date (date of first prescription of thyroid hormone) and was censored on the date of death or at the end of the study (December 31, 2018).

The Cox proportional hazard model was used to explore independent associations between hypothyroidism and mortality risk, and hazard ratios (HRs) were computed with 95\% confidence intervals (CI). We conducted multivariable adjustments for age, sex, and comorbidities that affect mortality. Sensitivity analyses were performed in three groups according to the follow-up duration ( $<1$ year, $\leq 1$ to $<3$ years, and $>3$ years) from initial treatment with levothyroxine. All statistical analyses were conducted using $\mathrm{R}$ (version 4.0.2).

\section{RESULTS}

\section{Baseline Characteristics of the Cohort}

A total of 501,882 patients with hypothyroidism and 1,505,646 controls treated between January 2008 and December 2017 were included. Baseline characteristics of the subjects are presented in Table 1. The mean age was 50.6 years, and women were 
TABLE 1 | Baseline characteristics of the study populations.

\begin{tabular}{lcc}
\hline & Hypothyroidism cohort & Control cohort \\
\hline Total & 501,882 & $1,505,646$ \\
Male & $87,233(17.4 \%)$ & $261,699(17.4 \%)$ \\
Female & $414,649(82.6 \%)$ & $1,243,947(82.6 \%)$ \\
Age & & \\
mean \pm SD & $50.6 \pm 15.0$ & $50.6 \pm 15.0$ \\
$<65$ years & $404,230(80.5 \%)$ & $1,212,690(80.5 \%)$ \\
$\geq 65$ years & $97,652(19.5 \%)$ & $292,956(19.5 \%)$ \\
Days of prescription & & \\
$<2$ years & $191,185(38 \%)$ & \\
$\leq 2$ to $<4$ years & $111,937(22 \%)$ & \\
$\leq 4$ to $<6$ years & $78,332(16 \%)$ & \\
$\leq 6$ years & $120,428(24 \%)$ & \\
Comorbidities & & \\
Hypertension & $119,420(23.8 \%)$ & $123,070(8.2 \%)$ \\
Diabetes & $62,441(12.4 \%)$ & $5,818(0.4 \%)$ \\
Myocardial infarction & $3,303(0.7 \%)$ & $42,165(2.8 \%)$ \\
Stroke & $18,186(3.6 \%)$ & $12,737(0.8 \%)$ \\
Heart failure & $8,901(1.8 \%)$ & $5,998(0.4 \%)$ \\
Renal failure & $8,370(1.7 \%)$ & $33,485(2.2 \%)$ \\
Malignancy & $20,997(4.2 \%)$ & $<0.001$ \\
\hline
\end{tabular}

SD, standard deviation.

predominant (82.6\%). Hypothyroid patients had a significantly higher prevalence of all selected comorbidities than the control cohort. The mean follow-up durations were 71.6 [standard deviation (SD), 35.6] months and 72.1 (SD, 35.4) months for the hypothyroid and control cohorts, respectively.

\section{Impact of Hypothyroidism on the All-Cause Mortality}

Cumulative mortality risk is illustrated in Figure 2. The mortality rate of hypothyroid patients was higher than that of the control cohort (Table 2). During the follow-up period, 25,954 (5.2\%) hypothyroid patients died, compared with 59,105 (3.9\%) controls. The crude mortality rate among hypothyroid patients was 8.66 per 1,000 person-years, compared with 6.53 per 1,000 person-years in the control cohort. When stratified by age, sex, and CVD, the crude mortality rate was consistently higher in all subgroups of the hypothyroid cohort.

Cox proportional hazards analyses revealed that the mortality risk in hypothyroid subjects was higher than that in controls. The crude HR was 1.33 (95\% CI: 1.31-1.35) and adjusted HR was 1.14 (95\% CI: 1.12-1.16) (Table 2). When stratified by age, sex, and CVD risk, an independent association between hypothyroidism and mortality remained significant in all subgroups. The risk of mortality was higher in the $<65$ age group (HR: 1.25, 95\% CI: 1.22-1.29), men (HR: 1.28, 95\% CI: 1.25-1.31), and the high CVD risk group (HR: 1.31, 95\% CI: 1.29-1.34) than in subgroups $\geq 65$ years (HR: $1.08,95 \%$ CI: $1.06-1.10$ ), women

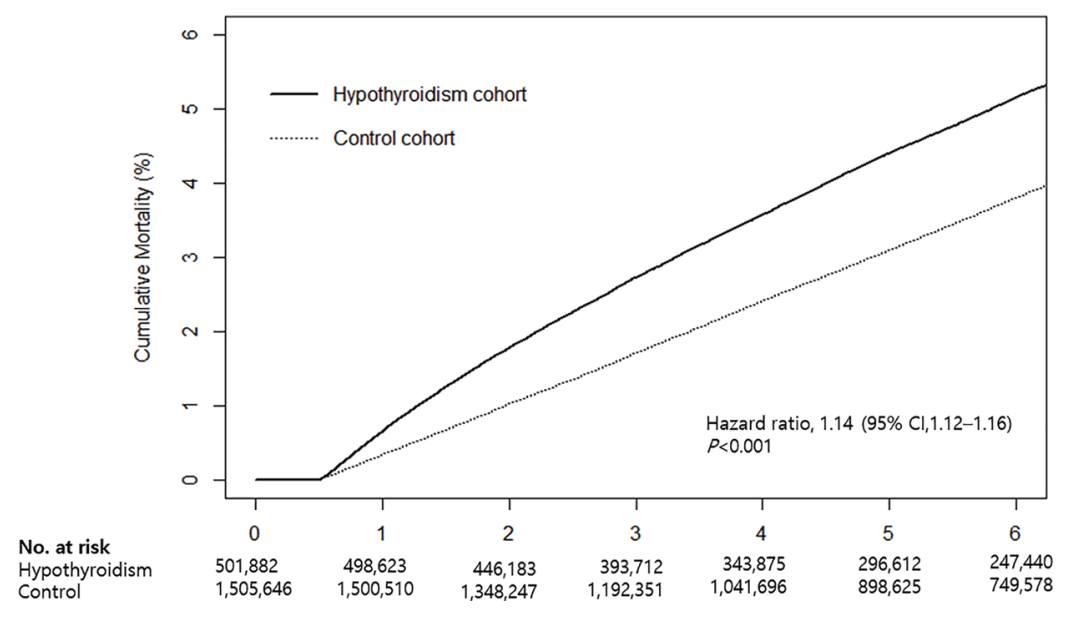

FIGURE 2 | Kaplan-Meier curves for cumulative mortality in hypothyroid patients and the control cohort. 
TABLE 2 | Incidence rates and hazard ratios for mortality in the hypothyroidism cohort and the control cohort.

\begin{tabular}{|c|c|c|c|c|c|c|}
\hline \multirow[b]{2}{*}{ Subgroup } & \multicolumn{2}{|c|}{ Hypothyroidism cohort } & \multicolumn{2}{|c|}{ Control cohort } & \multicolumn{2}{|c|}{ Hazard ratio for mortality } \\
\hline & Number of deaths & $\begin{array}{c}\text { Mortality rate }[\mathrm{Cl}] \\
\text { (per } 1,000 \text { person-years) }\end{array}$ & Number of deaths & $\begin{array}{c}\text { Mortality rate }[\mathrm{Cl}] \\
\text { (per } 1,000 \text { person-years) }\end{array}$ & Crude $\mathrm{HR}^{\star}[\mathrm{Cl}]$ & Adjusted $\mathrm{HR}^{\star \star}[\mathrm{Cl}]$ \\
\hline All & 25,954 & 8.66 [8.33-9.00] & 59,105 & $6.53[6.37-6.70]$ & $\begin{array}{c}1.33 \\
{[1.31-1.35]}\end{array}$ & $\begin{array}{c}1.14 \\
{[1.12-1.16]}\end{array}$ \\
\hline Male & 11,470 & 24.44 [23.04-25.90] & 23,211 & 16.03 [15.38-16.69] & $\begin{array}{c}1.53 \\
{[1.49-1.56]}\end{array}$ & $\begin{array}{c}1.28 \\
{[1.25-1.31]}\end{array}$ \\
\hline Female & 14,484 & $5.73[5.44-6.04]$ & 35,894 & $4.72[4.57-4.88]$ & $\begin{array}{c}1.21 \\
{[1.19-1.24]}\end{array}$ & $\begin{array}{c}1.06 \\
{[1.04-1.09]}\end{array}$ \\
\hline \multicolumn{7}{|l|}{ Age groups } \\
\hline$<65$ years & 8,649 & 3.49 [3.26-3.73] & 16,275 & 2.18 [2.07-2.29] & $\begin{array}{c}1.60 \\
{[1.56-1.64]}\end{array}$ & $\begin{array}{c}1.25 \\
{[1.22-1.29]}\end{array}$ \\
\hline$\geq 65$ years & 17,305 & 33.69 [32.12-35.32] & 42,830 & 27.25 [26.44-28.07] & $\begin{array}{c}1.24 \\
{[1.22-1.26]}\end{array}$ & $\begin{array}{c}1.08 \\
{[1.06-1.10]}\end{array}$ \\
\hline \multicolumn{7}{|l|}{ Comorbidities } \\
\hline Low CVD risk group & 8,111 & $3.64[3.40-3.90]$ & 25,157 & $3.52[3.39-3.66]$ & $\begin{array}{c}1.03 \\
{[1.01-1.06]}\end{array}$ & $\begin{array}{c}1.10 \\
{[1.08-1.13]}\end{array}$ \\
\hline High CVD ${ }^{\star \star \star}$ risk group & 17,843 & 23.19 [22.13-24.30] & 33,948 & $17.81[17.22-18.42]$ & $\begin{array}{c}1.30 \\
{[1.28-1.33]}\end{array}$ & $\begin{array}{c}1.31 \\
{[1.29-1.34]}\end{array}$ \\
\hline
\end{tabular}

Cl, confidence interval; CVD, cardiovascular disease.

${ }^{*}$ Reference group is the control cohort.

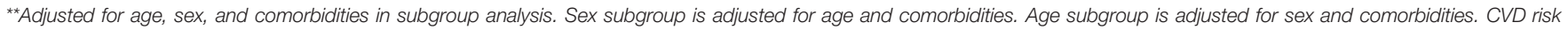
subgroup is adjusted for age and sex.

${ }^{* * *}$ High CVD risk group is defined as the presence of hypertension, diabetes mellitus, or prevalent CVD (MI, stroke, and heart failure).

(HR: 1.06, 95\% CI: 1.04-1.09), and low CVD risk (HR: 1.10, 95\% CI: $1.08-1.13)$.

In sensitivity analyses according to follow-up duration, mortality risk increased in the hypothyroid cohort at $<1$ year, $\leq 1-3$ years, and $\geq 3$ years after initial treatment with levothyroxine, but this association tended to decrease as the follow-up time increased (Table 3). The mortality rate in hypothyroid patients was the highest within 1 year of treatment and decreased with time.

\section{DISCUSSION}

In this nationwide, retrospective population-based cohort study, we found that hypothyroidism was associated with an increased risk of all-cause mortality. This association remained significant regardless of age, sex, and CVD risk.

Many previous studies have investigated the link between hypothyroidism and mortality risk, but their results have been inconsistent $(11-24,28-34)$. Possible reasons for such discrepancies include considerable variations in the definition and severity of hypothyroidism, characteristics of study populations, and adjustments for comorbidities. Many studies have defined hypothyroidism based on a single measurement of TSH level and have used different reference ranges $(13,15,22,28$, $30,37)$, which carries the possibility of phenotype misclassification, as spontaneous normalization of an abnormally elevated TSH may occur in a substantial proportion of individuals (41). With regard to study populations, studies based on hospitalized patients have indicated a positive correlation between serum TSH concentration

TABLE 3 | Hazard ratios for all-cause mortality stratified by follow-up duration after initial treatment.

\begin{tabular}{|c|c|c|c|c|}
\hline Subgroup & \multicolumn{4}{|c|}{ Adjusted $\mathrm{HR}^{\star}[\mathrm{Cl}]$} \\
\hline All & $1.14[1.12-1.16]$ & $1.50[1.44-1.57]$ & $1.27[1.24-1.30]$ & 1.01 [0.99-1.03] \\
\hline Male & $1.28[1.25-1.31]$ & $1.82[1.71-1.95]$ & $1.43[1.38-1.49]$ & $1.08[1.04-1.11]$ \\
\hline Female & $1.06[1.04-1.09]$ & $1.28[1.20-1.37]$ & $1.17[1.13-1.21]$ & 0.98 [0.96-1.01] \\
\hline \multicolumn{5}{|l|}{ Age } \\
\hline$<65$ years & $1.25[1.22-1.29]$ & $1.81[1.66-1.97]$ & $1.53[1.46-1.60]$ & 1.05 [1.01-1.09] \\
\hline Low CVD risk group & $1.10[1.08-1.13]$ & $1.57[1.44-1.70]$ & $1.30[1.24-1.36]$ & 0.96 [0.93-0.99] \\
\hline High CVD*^ risk group & $1.31[1.29-1.34]$ & $1.72[1.63-1.81]$ & $1.45[1.40-1.49]$ & $1.15[1.12-1.18]$ \\
\hline
\end{tabular}

$\mathrm{Cl}$, confidence interval; CVD, cardiovascular disease.

${ }^{*}$ Adjusted for age, sex, and comorbidities in subgroup analysis. Sex subgroup is adjusted for age and comorbidities. Age subgroup is adjusted for sex and comorbidities. CVD risk subgroup is adjusted for age and sex. 
and mortality risk $(13,42)$, whereas no increased mortality risk has been reported in hypothyroid subjects in primary care settings compared with the euthyroid population $(11,15,20)$. In addition, some studies did not adequately adjust for comorbid conditions (11, $15,24,42)$. Our definition of hypothyroidism, as individuals treated with levothyroxine for $>6$ months, may solely represent overt hypothyroidism in real clinical practice. After adjustment for various comorbidities that affect mortality, hypothyroidism was still associated with $14 \%$ excess mortality when compared with controls. In line with our findings, Huang et al. also reported increased mortality in older ( $>65$ years) hypothyroid subjects taking thyroid hormones when compared with non-hypothyroid individuals (12). Our results are also in agreement with those of recent meta-analyses $(14,19)$. A meta-analysis of 55 cohort studies, with no restrictions on age or degree of hypothyroidism, showed that hypothyroidism was associated with a higher risk of all-cause mortality than the euthyroid state (relative risk, 1.25; 95\% CI: 1.131.39) (14). Another meta-analysis of 27 cohort studies focusing on the elderly population observed a significant association with increased all-cause mortality in patients with overt hypothyroidism, but not in those with subclinical hypothyroidism (19).

There are several plausible explanations for the increased risk of mortality in levothyroxine-treated hypothyroid patients in this study. First, it is possible that patients with severe hypothyroidism who were untreated for a long time have been included, although the medical records or thyroid function tests of enrolled patients in this study are not known. Second, treatment with levothyroxine may not fully reverse CVD risk factors that lead to increased mortality. Third, it is possible that hypothyroidism has either been over- or under-treated.

In the present study, patients with hypothyroidism had significantly higher prevalence of comorbidities than the control group. First, the higher prevalence of comorbidities in hypothyroid patients can plausibly be explained by the biological action of hypothyroidism itself. Hypothyroidism is known to induce many effects on the cardiovascular system, such as systolic and diastolic dysfunction, endothelial dysfunction, atherogenic lipid profiles, hypertension, and insulin resistance (6-10). A number of population studies have reported higher prevalence of atherosclerotic cardiovascular events and heart failure in hypothyroid patients $(13-15,28,33)$. In addition, decreased hemodynamics in the circulatory system lead to declines in GFR in severe hypothyroidism (39). Second, it may be explained by the surveillance effect. Patients with comorbidities are more likely to visit clinics and undergo thyroid function tests than the subjects without comorbidities. Therefore, hypothyroidism is more likely to be detected in individuals with underlying disease.

Previous studies have suggested that the association between hypothyroidism and mortality is dependent on underlying comorbidities, especially CVD $(13,16)$. Studies in populations with high underlying CVD risk have shown that hypothyroidism is associated with higher all-cause and cardiovascular mortality $(13,23,36,37,43)$. In a meta-analysis by Rodondi et al., the association between subclinical hypothyroidism and mortality did not differ according to pre-existing CVD (31). In the present study, we found that hypothyroidism is associated with higher all-cause mortality, with or without underlying CVD, although the association seemed to be more significant in the presence of CVD. Considering the impact of hypothyroidism on atherosclerosis, cardiac contractility, and arrhythmia, its association with higher mortality is plausible, particularly in populations with underlying CVD.

The risk of mortality in hypothyroidism may differ by age and sex $(18,20,24,28,32,34,38)$. Previous studies have suggested that the association between hypothyroidism and mortality is less evident in individuals aged $>65$ years $(20,32,34,44)$. Recently, Peng et al. found that the use of thyroid hormone replacement was not associated with all-cause mortality in patients aged $>65$ years with subclinical hypothyroidism (38). The Leiden $85+$ study, which enrolled individuals aged 85 years and older, indicated a decreased risk of cardiovascular and all-cause mortality with higher TSH levels (18), but these findings have not been replicated. Some studies have found increased risk of mortality only in male subjects with subclinical hypothyroidism $(24,28)$ while others have not (30). In the present study, the increased risk of mortality in hypothyroidism was consistently significant in ageand sex-stratified analyses, with the HR for mortality being higher in the younger age group and in men, which partly corroborated the results of previous studies.

In the present study, the mortality rate of hypothyroid patients increased regardless of age, sex, and CVD risk, but the HR for mortality decreased as the duration of thyroid hormone treatment increased. There are several plausible explanations for the higher mortality risk observed during initial treatment for hypothyroidism. First, the index date when hypothyroid patients were enrolled was defined as the date of first prescription of levothyroxine. Given that some hypothyroid patients may have been untreated for long periods of time before initiating thyroid hormone, there is a possibility that a large number of patients with hypothyroidism died during the early periods of therapy due to comorbidities associated with hypothyroidism. Second, mortality might increase during the early period of treatment due to under- or over-treatment. Thyroid function is more likely to be stable over a longer period of treatment; therefore, the mortality risk of hypothyroidism may be similar to that of the general population if euthyroid state is maintained. Thayakaran et al. found that hypothyroidism did not affect mortality when TSH concentrations were within the recommended normal limits (45). However, this finding was not confirmed in the present study owing to the absence of individual thyroid function tests.

The main strengths of our study include the large hypothyroid cohort of 501,882 individuals, the use of real-world data from primary care settings, and access to complete follow-up data. However, this study had several limitations. The diagnoses of hypothyroidism used in the study were based on administrative claims data, which may be less accurate than diagnoses based on biochemical data, as in other registry-based studies. It is possible that the hypothyroidism cohort includes patients with subclinical hypothyroidism who were asymptomatic but received a levothyroxine prescription after undergoing thyroid function tests. However, since the hypothyroidism cohort only targeted patients 
who took levothyroxine for more than 6 months, patients who took levothyroxine temporarily were likely to have been excluded. It is also possible that some patients with subclinical hypothyroidism were classified in the control cohort because the prevalence of subclinical hypothyroidism is about $3 \%$ in the general Korean population (46). Therefore, misclassification affects both the hypothyroidism cohort and the control cohort, and thus most likely does not affect our mortality risk estimates. It was impossible to obtain precise information concerning the timing of onset or duration of hypothyroidism, as was included in previous registry-based studies. Although thyroid function tests and the medical records of patients enrolled in the present study were unknown, patients with severe hypothyroidism who were untreated for long periods of time may have been included. Whether levothyroxine treated patients recovered to euthyroid state is unknown. However, we deduce that mortality tends to decrease in levothyroxine treated hypothyroid patients, as thyroid function is likely to be stable over time, because hazard ratios for mortality decreased as the duration of thyroid hormone treatment increased in our study. Lastly, although we adjusted for various underlying comorbidities, data for other potential confounders such as smoking status, body mass index, and alcohol consumption were not available.

In conclusion, in this nationwide, population-based cohort study we found that all-cause mortality was significantly higher in levothyroxine-treated hypothyroid patients than in non-hypothyroid controls. This association remained significant regardless of the age, sex, and cardiovascular disease risk. Further prospective cohort studies on the effects of hypothyroidism and levothyroxine treatment on mortality are warranted.

\section{REFERENCES}

1. Hollowell JG, Staehling NW, Flanders WD, Hannon WH, Gunter EW, Spencer CA, et al. Serum TSH, T(4), and Thyroid Antibodies in the United States Population (1988 to 1994): National Health and Nutrition Examination Survey (Nhanes III). J Clin Endocrinol Metab (2002) 87:489-99. doi: 10.1210/ jcem.87.2.8182

2. Seo GH, Chung JH. Incidence and Prevalence of Overt Hypothyroidism and Causative Diseases in Korea as Determined Using Claims Data Provided by the Health Insurance Review and Assessment Service. Endocrinol Metab (Seoul) (2015) 30:288-96. doi: 10.3803/EnM.2015.30.3.288

3. Canaris GJ, Manowitz NR, Mayor G, Ridgway EC. The Colorado Thyroid Disease Prevalence Study. Arch Intern Med (2000) 160:526-34. doi: 10.1001/ archinte.160.4.526

4. Carlé A, Laurberg P, Pedersen IB, Knudsen N, Perrild H, Ovesen L, et al. Epidemiology of Subtypes of Hypothyroidism in Denmark. Eur J Endocrinol (2006) 154:21-8. doi: 10.1530/eje.1.02068

5. Kim HI, Oh HK, Park SY, Jang HW, Shin MH, Han JM, et al. Non-ImmuneRelated Hypothyroidism and its Relationship With Excess Iodine. Eur J Nutr (2019) 58:2851-8. doi: 10.1007/s00394-018-1837-4

6. Cai Y, Ren Y, Shi J. Blood Pressure Levels in Patients With Subclinical Thyroid Dysfunction: A Meta-Analysis of Cross-Sectional Data. Hypertens Res (2011) 34:1098-105. doi: 10.1038/hr.2011.91

7. Erem C. Thyroid Disorders and Hypercoagulability. Semin Thromb Hemost (2011) 37:17-26. doi: 10.1055/s-0030-1270067

8. Lekakis J, Papamichael C, Alevizaki M, Piperingos G, Marafelia P, Mantzos J, et al. Flow-Mediated, Endothelium-Dependent Vasodilation is Impaired in Subjects With Hypothyroidism, Borderline Hypothyroidism, and High-

\section{DATA AVAILABILITY STATEMENT}

Data are available through the Health Insurance Review and Assessment Service in Korea 279 (HIRA). Researchers who wish to access the data can apply at (https://www.hira.or.kr).

\section{ETHICS STATEMENT}

The studies involving human participants were reviewed and approved by Health Insurance Review and Assessment Service in Korea (Approval no. 2020-069). The ethics committee waived the requirement of written informed consent for participation.

\section{AUTHOR CONTRIBUTIONS}

SS and GS designed the study and wrote the manuscript. GS had access to all the data. SS and GS analyzed the data. JC was responsible for the decision to submit the manuscript. All authors contributed to the article and approved the submitted version.

\section{FUNDING}

This work was supported by the Samjung Scholarship Foundation and by the faculty grant of Myongji Hospital (2002-09-07) to SS.

Normal Serum Thyrotropin (TSH) Values. Thyroid (1997) 7:411-4. doi: 10.1089/thy.1997.7.411

9. Klein I, Danzi S. Thyroid Disease and the Heart. Circulation (2007) 116:172535. doi: 10.1161/CIRCULATIONAHA.106.678326

10. O'Brien T, Dinneen SF, O'Brien PC, Palumbo PJ. Hyperlipidemia in Patients With Primary and Secondary Hypothyroidism. Mayo Clin Proc (1993) 68:860-6. doi: 10.1016/s0025-6196(12)60694-6

11. Flynn RW, Macdonald TM, Jung RT, Morris AD, Leese GP. Mortality and Vascular Outcomes in Patients Treated for Thyroid Dysfunction. J Clin Endocrinol Metab (2006) 91:2159-64. doi: 10.1210/jc.2005-1833

12. Huang HK, Wang JH, Kao SL. Association of Hypothyroidism With AllCause Mortality: A Cohort Study in an Older Adult Population. J Clin Endocrinol Metab (2018) 103:3310-8. doi: 10.1210/jc.2018-00408

13. McQuade C, Skugor M, Brennan DM, Hoar B, Stevenson C, Hoogwerf BJ. Hypothyroidism and Moderate Subclinical Hypothyroidism are Associated With Increased All-Cause Mortality Independent of Coronary Heart Disease Risk Factors: A PreCIS Database Study. Thyroid (2011) 21:837-43. doi: $10.1089 /$ thy.2010.0298

14. Ning Y, Cheng YJ, Liu LJ, Sara JD, Cao ZY, Zheng WP, et al. What is the Association of Hypothyroidism With Risks of Cardiovascular Events and Mortality? A Meta-Analysis of 55 Cohort Studies Involving 1,898,314 Participants. BMC Med (2017) 15:21. doi: 10.1186/s12916-017-0777-9

15. Selmer C, Olesen JB, Hansen ML, von Kappelgaard LM, Madsen JC, Hansen PR, et al. Subclinical and Overt Thyroid Dysfunction and Risk of All-Cause Mortality and Cardiovascular Events: A Large Population Study. J Clin Endocrinol Metab (2014) 99:2372-82. doi: 10.1210/jc.2013-4184

16. Thvilum M, Brandt F, Almind D, Christensen K, Hegedus L, Brix TH. Excess Mortality in Patients Diagnosed With Hypothyroidism: A Nationwide Cohort 
Study of Singletons and Twins. J Clin Endocrinol Metab (2013) 98:1069-75. doi: 10.1210/jc.2012-3375

17. Grossman A, Weiss A, Koren-Morag N, Shimon I, Beloosesky Y, Meyerovitch J. Subclinical Thyroid Disease and Mortality in the Elderly: A Retrospective Cohort Study. Am J Med (2016) 129:423-30. doi: 10.1016/j.amjmed. 2015.11.027

18. Gussekloo J, van Exel E, de Craen AJ, Meinders AE, Frölich M, Westendorp RG. Thyroid Status, Disability and Cognitive Function, and Survival in Old Age. Jama (2004) 292:2591-9. doi: 10.1001/jama.292.21.2591

19. Tsai TY, Tu YK, Munir KM, Lin SM, Chang RH, Kao SL, et al. Association of Hypothyroidism and Mortality in the Elderly Population: A Systematic Review and Meta-Analysis. J Clin Endocrinol Metab (2020) 105:2068-80. doi: $10.1210 /$ clinem/dgz186

20. Waring AC, Harrison S, Samuels MH, Ensrud KE, Le BES, Hoffman AR, et al. Thyroid Function and Mortality in Older Men: A Prospective Study. J Clin Endocrinol Metab (2012) 97:862-70. doi: 10.1210/jc.2011-2684

21. Moon S, Kim MJ, Yu JM, Yoo HJ, Park YJ. Subclinical Hypothyroidism and the Risk of Cardiovascular Disease and All-Cause Mortality: A Meta-Analysis of Prospective Cohort Studies. Thyroid (2018) 28:1101-10. doi: 10.1089/ thy.2017.0414

22. Laulund AS, Nybo M, Brix TH, Abrahamsen B, Jorgensen HL, Hegedus L. Duration of Thyroid Dysfunction Correlates With All-Cause Mortality. The OPENTHYRO Register Cohort. PloS One (2014) 9:e110437. doi: 10.1371/ journal.pone.0110437

23. Iervasi G, Molinaro S, Landi P, Taddei MC, Galli E, Mariani F, et al. Association Between Increased Mortality and Mild Thyroid Dysfunction in Cardiac Patients. Arch Intern Med (2007) 167:1526-32. doi: 10.1001/ archinte.167.14.1526

24. Kovar FM, Fang IF, Perkmann T, Haslacher H, Slavka G, Födinger M, et al. Subclinical Hypothyroidism and Mortality in a Large Austrian Cohort: A Possible Impact on Treatment? Wien Klin Wochenschr (2015) 127:924-30. doi: 10.1007/s00508-015-0846-z

25. Garber JR, Cobin RH, Gharib H, Hennessey JV, Klein I, Mechanick JI, et al. Clinical Practice Guidelines for Hypothyroidism in Adults: Cosponsored by the American Association of Clinical Endocrinologists and the American Thyroid Association. Thyroid (2012) 22:1200-35. doi: 10.1089/thy.2012.0205

26. Peterson SJ, McAninch EA, Bianco AC. Is a Normal Tsh Synonymous With "Euthyroidism" in Levothyroxine Monotherapy? J Clin Endocrinol Metab (2016) 101:4964-73. doi: 10.1210/jc.2016-2660

27. Samuels MH, Kolobova I, Smeraglio A, Peters D, Purnell JQ, Schuff KG. Effects of Levothyroxine Replacement or Suppressive Therapy on Energy Expenditure and Body Composition. Thyroid (2016) 26:347-55. doi: 10.1089/ thy.2015.0345

28. Imaizumi M, Akahoshi M, Ichimaru S, Nakashima E, Hida A, Soda M, et al. Risk for Ischemic Heart Disease and All-Cause Mortality in Subclinical Hypothyroidism. J Clin Endocrinol Metab (2004) 89:3365-70. doi: 10.1210/ jc.2003-031089

29. Razvi S, Weaver JU, Butler TJ, Pearce SH. Levothyroxine Treatment of Subclinical Hypothyroidism, Fatal and Nonfatal Cardiovascular Events, and Mortality. Arch Intern Med (2012) 172:811-7. doi: 10.1001/archinternmed.2012.1159

30. Cappola AR, Fried LP, Arnold AM, Danese MD, Kuller LH, Burke GL, et al. Thyroid Status, Cardiovascular Risk, and Mortality in Older Adults. Jama (2006) 295:1033-41. doi: 10.1001/jama.295.9.1033

31. Rodondi N, den Elzen WP, Bauer DC, Cappola AR, Razvi S, Walsh JP, et al. Subclinical Hypothyroidism and the Risk of Coronary Heart Disease and Mortality. Jama (2010) 304:1365-74. doi: 10.1001/jama.2010.1361

32. Ceresini G, Ceda GP, Lauretani F, Maggio M, Usberti E, Marina M, et al. Thyroid Status and 6-Year Mortality in Elderly People Living in a Mildly Iodine-Deficient Area: The Aging in the Chianti Area Study. J Am Geriatr Soc (2013) 61:868-74. doi: 10.1111/jgs.12267

33. Tseng FY, Lin WY, Lin CC, Lee LT, Li TC, Sung PK, et al. Subclinical Hypothyroidism is Associated With Increased Risk for All-Cause and
Cardiovascular Mortality in Adults. J Am Coll Cardiol (2012) 60:730-7. doi: 10.1016/j.jacc.2012.03.047

34. Razvi S, Shakoor A, Vanderpump M, Weaver JU, Pearce SH. The Influence of Age on the Relationship Between Subclinical Hypothyroidism and Ischemic Heart Disease: A Metaanalysis. J Clin Endocrinol Metab (2008) 93:2998-3007. doi: 10.1210/jc.2008-0167

35. Akirov A, Gimbel H, Grossman A, Shochat T, Shimon I. Elevated TSH in Adults Treated for Hypothyroidism is Associated With Increased Mortality. Eur J Endocrinol (2017) 176:57-66. doi: 10.1530/eje-16-0708

36. Lin HJ, Lin CC, Lin HM, Chen HJ, Lin CC, Chang CT, et al. Hypothyroidism is Associated With All-Cause Mortality in a National Cohort of Chronic Haemodialysis Patients. Nephrol (Carlton) (2018) 23:559-64. doi: 10.1111/ nep. 13049

37. Rhee CM, Kalantar-Zadeh K, Ravel V, Streja E, You AS, Brunelli SM, et al. Thyroid Status and Death Risk in US Veterans With Chronic Kidney Disease. Mayo Clin Proc (2018) 93:573-85. doi: 10.1016/j.mayocp.2018.01.024

38. Peng CC, Huang HK, Wu BB, Chang RH, Tu YK, Munir KM. Association of Thyroid Hormone Therapy With Mortality in Subclinical Hypothyroidism: A Systematic Review and Meta-Analysis. J Clin Endocrinol Metab (2021) 106:292-303. doi: 10.1210/clinem/dgaa777

39. den Hollander JG, Wulkan RW, Mantel MJ, Berghout A. Correlation Between Severity of Thyroid Dysfunction and Renal Function. Clin Endocrinol (Oxf) (2005) 62:423-7. doi: 10.1111/j.1365-2265.2005.02236.x

40. Available at: http://kostat.go.kr/portal/korea/kor_nw/1/6/2/index.board (Accessed 13 April, 2021).

41. Díez JJ, Iglesias P. Spontaneous Subclinical Hypothyroidism in Patients Older Than 55 Years: An Analysis of Natural Course and Risk Factors for the Development of Overt Thyroid Failure. J Clin Endocrinol Metab (2004) 89:4890-7. doi: 10.1210/jc.2003-032061

42. Maldonado LS, Murata GH, Hershman JM, Braunstein GD. Do Thyroid Function Tests Independently Predict Survival in the Critically Ill? Thyroid (1992) 2:119-23. doi: 10.1089/thy.1992.2.119

43. Molinaro S, Iervasi G, Lorenzoni V, Coceani M, Landi P, Srebot V, et al. Persistence of Mortality Risk in Patients With Acute Cardiac Diseases and Mild Thyroid Dysfunction. Am J Med Sci (2012) 343:65-70. doi: 10.1097/ MAJ.0b013e31822846bd

44. Du Puy RS, Poortvliet RKE, Mooijaart SP, den Elzen WPJ, Jagger C, Pearce SHS, et al. Outcomes of Thyroid Dysfunction in People Aged Eighty Years and Older: An Individual Patient Data Meta-Analysis of Four Prospective Studies (Towards Understanding Longitudinal International Older People Studies Consortium). Thyroid (2020) 31(4):552-62. doi: 10.1089/thy.2020.0567

45. Thayakaran R, Adderley NJ, Sainsbury C, Torlinska B, Boelaert K, Šumilo D, et al. Thyroid Replacement Therapy, Thyroid Stimulating Hormone Concentrations, and Long Term Health Outcomes in Patients With Hypothyroidism: Longitudinal Study. Bmj (2019) 366:14892. doi: 10.1136/ bmj.14892

46. Kim WG, Kim WB, Woo G, Kim H, Cho Y, Kim TY, et al. Thyroid Stimulating Hormone Reference Range and Prevalence of Thyroid Dysfunction in the Korean Population: Korea National Health and Nutrition Examination Survey 2013 to 2015. Endocrinol Metab (Seoul) (2017) 32:106-14. doi: 10.3803/EnM.2017.32.1.106

Conflict of Interest: The authors declare that the research was conducted in the absence of any commercial or financial relationships that could be construed as a potential conflict of interest.

Copyright (๑) 2021 Sohn, Seo and Chung. This is an open-access article distributed under the terms of the Creative Commons Attribution License (CC BY). The use, distribution or reproduction in other forums is permitted, provided the original author(s) and the copyright owner(s) are credited and that the original publication in this journal is cited, in accordance with accepted academic practice. No use, distribution or reproduction is permitted which does not comply with these terms. 